\title{
Framing of media coverage of the Palestinian - Israeli conflict in CNN and FoxNews
}

\author{
Suzan Alkalliny
}

\author{
Department of Media, Faculty of Arts, Ain Shams University, Cairo, Egypt
}

\begin{abstract}
Use of media, especially television, is an important point in the history of important events and recent wars. This type of media coverage of events and wars transfers the audience to the heart of the event and has a direct impact on public opinion internationally. For example, much criticism has been directed at the American media regarding coverage of the Israeli aggression on Gaza. Many demonstrations against the two largest networks in the United States, CNN and FOXNEWS, have also taken place in New York City to protest against the biased media coverage of the Palestinians and the Israeli aggression against Gaza.This paper contains various news frameworks used in media coverage of events and its result and impact on different audiences. In conclusion, the study addressing the mentioned conflict declared that the coverage was biased and non-objective, relying heavily on Israeli sources in comparison to Palestinian sources.
\end{abstract}

Keywords-media coverage, CNN, FoxNews, Palestinian -Israeli.

\section{INTRODUCTION}

The use of the media, especially television, is an important point in the history of important events and modern wars even the Second Gulf War was named by "Air war" because $\mathrm{CNN}$ broadcasted the events of the war on air directly to the homes of the viewers, and this kind of media coverage of events and wars to transfer the viewer to the heart of the event and leads to a direct impact on public opinion both internally and externally.

The two parties of the conflict, which is being televised, are trying to impose their views and influence on the public opinion through the framework of media coverage, which is transmitted within news framework. At the beginning of the Israeli aggression, which began on 8 July 2014 and lasted 51 days, killing 2322 Palestinians and injuring thousands, the Arab and foreign media have been competing to cover the events and their successive developments. The major news networks have also sent their delegates and correspondents to the Gaza Strip for the rapid broadcast of the events of the conflict.
Much of the criticism has been directed at the American media regarding the coverage of the Israeli aggression on Gaza. Many demonstrations against the two largest American networks in the United States of America, CNN and FOX News in New York, have also been held in protest against the biased media coverage of the Palestinians.

The demonstrators launched a number of cheers condemning the bias of the media coverage of the American networks CNN and FOX News. This study seeks to monitor the media coverage of the two networks and the news coverage of the Israeli aggression on Gaza 2014 and the events of 2017 in the context of the theory of news frameworks.

\section{Theory of media frameworks as an input to the study:}

This study uses the theory of news frameworks: a theoretical framework for the study according to the nature of the framework, which gives meaning to the news and is divided into:

\section{Episodic Frame}

It focuses on the event being covered without regard to the context associated with the event or its background. This framework depicts general issues in the form of individual factual situations.

\section{Thematic Frame}

This framework addresses the issues raised simply and general and takes into account the context and the political, economic and social conditions as well as international variables, which means that the news appears within the policy of the state to which the media belongs.

This study will draw on frameworks according to issues and events, which in turn are divided into:

\section{1- Strategic Frameworks}

This framework focuses on events in their strategic context affecting the national security of the state and fits with political and military events.

\section{2- Conflict Frameworks}

It is the most widely used and used to cover news issues as there are frameworks that ' contain a great deal of conflict such as events (terrorism - wars armed conflict) 
Frameworks of conflict (corruption issues - military maneuvers) and finally frameworks based on limited conflict such as human competition - environmental issues.

\section{3- Liability frameworks}

It links the responsibility of an individual or entity to the issue at hand

\section{4- Economic Results Frameworks}

They address the issue in the context of the reflection of its results on society, groups and individuals.

\section{5- Framework of humanitarian meetings}

It adds a human or emotional dimension to the event or issue by using emotional words and dramatic treatment of the event.

Although there are many classifications of frames, frames are the way in which the media describe the issue and the event through words, terms, sentences, phrases and images used to guide the recipient to draw conclusions and judgments about the issue or event.

This study employs the theory of media frameworks in monitoring and analyzing the frameworks of dealing with the Palestinian-Israeli conflict through the American networks CNN and FOX NEWS. This study is concerned with answering the following question:

"What are the media treatment frameworks for the Palestinian-Israeli conflict in Gaza 2014 and in the events of Al-Aqsa 2017?

The analysis was conducted on the CNN and FOX News channels for a period of (50 days) of 2014, the period of the Israeli aggression on Gaza and within two weeks of July 2017 is the period of the events of Al-Aqsa.

\section{The results of the study concluded that:}

- The media coverage of the Palestinian-Israeli conflict in Gaza in 2014 varied between CNN and FOX News.

CNN appeared more sympathetic to Israel, focusing on coverage of rockets fired from Gaza and completely ignoring the torrent of Israeli rockets destroyed hundreds of Palestinian sites.

The study also reported in the news reports between the military capability of the Israeli army and the ability of the Palestinian resistance.

The coverage appeared biased and non-objective as it relied heavily on Israeli sources compared to Palestinian sources during the first week of events as 54 Israeli figures appeared in contrastof 25 Palestinian figures from Hamas or the PLO. CNN also suspended Diana Magadi, after her tweet on Twitter in which she described the Israelis who danced and cheering on Taba on the border between Gaza and the occupied territories as "scum".
While Israeli figures in the FOX News channel were 62 figures versus 7 Palestinian figures (Figs. 1 and 2).

- Regarding FOX News, it showed a moral support in its media coverage of the Israeli aggression on Gaza for Israel and showed an anti-Arab stance. The media coverage of FOX News showed full support for Israel. The most important manifestations of bias were statements made by US Secretary of State John Kerry on the channel, in which the Israeli soldiers were killed and Israel's right to defend itself against Gaza rockets was confirmed. The channel also displayed a series of pictures of destroyed buildings in Gaza being in Israel, which is a deception to the viewers.

- CNN and FOX News have focused their coverage of the events of the Gaza conflict in 2014 on highlighting the conflict as a religious ethnic conflict rather than a conflict on land. The conflict was portrayed as a conflict between the militant Islamic group Hamas and Israel. The channel always uses the term "Militant Extremist Muslim ".

- The study showed that CNN and FOX News handled the events of Gaza 2014 as negative and biased in most of them. CNN relied on the frameworks of conflict and responsibility while FOX News relied on the frameworks of conflict and the economic consequences while the two channels completely diverged from the humanitarian and moral frameworks in the conflict in general and dominated the negative coverage on the media treatment of the events of Gaza in the channels of the study. (Figs. 3 and 4)

- The biased negative coverage of the events of the year 2017 continued towards the Palestiniansas the results of the study revealed that FOX News channel described the Palestinians as terrorists and stressed that the Palestinian side is the main reason for Al-Aqsa events and did not refer to the Israeli intransigence to put electronic gates and metal detectors to enter Al-Aqsa Mosque in any of the news. The conflict between Muslims and the Jews rather than the conflict between Israel and Palestine has transformed the conflict from political to religious.

- The use of religious terms in both channels increased in an attempt to frame the event in a religious rather than political context (Figs. 5 and 6).

- The results of the analysis revealed that the two channels were highly biased towards the Israeli side in the media coverage of the event.

- The impact of media coverage on American interests with Israel and political relations was noticed. FOX News focused on the economic repercussions of Al-Aqsa events, as well as $\mathrm{CNN}$, which did not express any humanitarian feelings in this conflict. The media coverage of the two channels did not refer to any of the images transmitted to 
Israeli soldiers which killed five Palestinians and injured hundreds in a week of Palestinian protests on the status of metal detectors at the entrances of Al-Aqsa Mosque in occupied East Jerusalem and the erection of electronic gates.

In the coverage of the two channels, the use of the terms of the police for Israelis and attackers for Palestinians is noted. - The media coverage of FOX News focused on Israeli military and security losses during the protests and clearly focused on showing Israeli military and security strength.

- While CNN was keen to justify Israel's establishment of egates at the entrance to Al-Aqsa Mosque, where Israel was portrayed as a victim while ignoring Palestinian casualties and presenting Israeli views while ignoring Palestinian views.

- Despite the allocation of the channels studied enough time to cover the events of Gaza 2014 and the protests of AlAqsa 2017, but CNN exceeded the amount of instant reports from the site of the event as well as the views of Israeli officials who appeared daily to comment frequently on events while FOX News relied on video footage and the news of US foreign agencies, as well as meetings with Israeli officials. Only some of the speakers of the political movements appeared from the Palestinians.

- The emergence of clear bias at the level of news discourse in the use of linkage clauses, news briefs and news prescriptions in describing Israel as the victim and defender of the protests carried out by the Palestinian side.

- FOX News used a number of arguments and evidence to support Israel's position while $\mathrm{CNN}$ used the political discourse through Israeli officials, emphasizing the pathways of proof that support Israel's image.

- A group of words was used to describe the Palestinian side, including the attackers, the terrorists, the despotic forces, and described the Israeli side as (the democratic forces - the military force - the self-defense and survival).

- The study revealed that the two channels clearly supported the Israeli forces against the Palestinians, both in the events of Gaza 2014 and in the protests of Al-Aqsa 2017.

- The study showed that the two channels participated in praising the policy of the United States of America as a powerful factor in resolving the crisis of conflict between Palestinians and Israelis in the events of Gaza 2014, while in the events of the Al-Aqsa 2017 devoted large areas to visit the envoy of US President Donald Trump to the Middle East Jession Greenblatt to Israel in an attempt to resolve the crisis and exaggerated the description of the role of the United States in the establishment of peace in the Middle East and in the rapid intervention to resolve the crisis of Al-
Aqsa, to cancel the security measures imposed recently in Al-Aqsa Mosque, which led to the outbreak of the crisis of Al-Aqsa.

- The study channels have criticized the Palestinian resistance and its image in a negative and sometimes cynical manner by focusing on the slogans used by the Palestinians and accusing them of ignorance and illiteracy.

- The study revealed that the treatment of the PalestinianIsraeli conflict since the events of Gaza 2014 and ending with the events of Al-Aqsa 2017 focused on specific frameworks in their media coverage, namely the frameworks of conflict - responsibility - economic consequences, which was prominent in the events of Gaza 2014, while the religious framework was added in the crisis of Al-Aqsa2017 so that it was used more than once (Muslims - Jews) and not Palestinians and Israelis. It was also noted that the media was completely devoid of humanitarian and moral frameworks that could change sympathy with the Palestinians and Human rights were not mentioned in any way.

- One of the most important observations in the framework of the responsibility used by $\mathrm{CNN}$ and has attributed by $\mathrm{CNN}$ is that the causes of the events is the Palestinians as they are the main reason for the start of the conflict in Gaza 2014 and in the protests of Al-Aqsa 2017 as a result of terrorist acts.

\section{Conclusion}

- The study found that CNN and FOX News are very biased towards the Israeli side in the framework of the media coverage, in the treatment of events, in the reliable sources, in the selection of pictures and videos, and in the justification presented to the Israeli side.

- The news coverage of the Palestinian-Israeli conflict is influenced by the political context of the state to which the channels belong and is also influenced by political interests between the United States and Israel.

- The media treatment of CNN and FOX NEWS channels has been linked to the principle of supporting the strategic interests of the United States of America.

- CNN and FOX NEWS channels manipulated the narrative structure of media treatment to serve American ideological and political purposes when dealing with the events of the Israeli-Palestinian conflict.

- The two channels have been involved in media manipulation of the Israeli-Palestinian conflict by shedding light on specific aspects and events of the news issue and the neglect of other aspects according to their political and ideological affiliation to become a tool to support the implementation of US foreign policy. 


\section{PROPOSALS}

In the context of the foregoing, we conclude the following proposals:

- The necessity for the Arab bloc to establish an international news channel that will broadcast in foreign languages and provide adequate funding for the nature of its work so that there is an international balance in the media treatment of Arab events, which are transmitted from one point of view.

- Since the news and drama are the most influential content in the public opinion at the level of the countries of the world, the Arab countries should start the establishment of an Arab drama production company so that the drama is a strong supporter of Arab issues at the international level.

- The establishment of an international news agency dedicated to the appropriate material and human resources. It will conduct balanced news coverage at the international level to ensure the presentation of different viewpoints

\section{REFERENCES}

[1] Media coverage of the Israel -Gaza conflict (2014) "Wikipedia available on www.aljazeera.net/internatioal (12-7-2014)

[2] Seth Ashle (2015) "making the case for war: a comparative analysis of $\mathrm{CNN}$ and $\mathrm{BBC}$ coverage of Colin Powell's presentation to the united nation security council " (base state university department of communication.

[3] Rebert M, Entman (1993) framing toward clarification of fractured paradigm " in journal of communication, vol. 43 no, 41993.

[4] Dietram, Ascheufele\& David twesbury (2007)" framing agenda setting and priming the evolution of three media effects model " journal of communication vol57, no 1, 2007.

[5] Esther lopatin\& others (2017) "a clash of civilization prism in German media? Documenting a shift from political to religious framing of the Israel - Palestinian conflict interdisciplinary center herzlia (IDC) Israel 2017.

[6] Gary R Edgerton (2016) " television "America " article , oxford research encyclopedias, (www.americanhistory,oxford.com)

[7] Matthew T.Haman (2008) "the media technology and united states foreign policy iare examination of the CNN effect, a journal of international affairs, 2008.

[8] Erin kribide (2015) the Middle East deserves more thoughtful coverage frame major vs. media, www.quz.com revolutionizing - mid - east coverage.

\section{CNN}

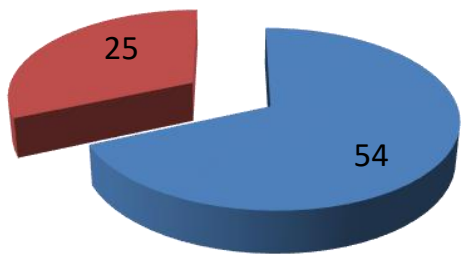

Israeli figures

Palestinian figures

\section{* Sources used in the channels of the study}

Fig.1: Media sources used by CNN

\section{FOX NEWS}

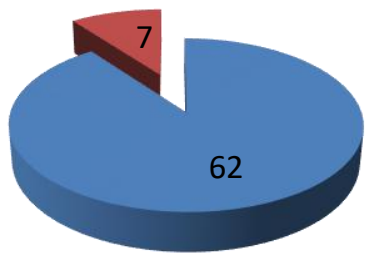

Israeli figures

Palestinian figures
Fig.1: Media sources used in FOX News

* Frames used in the media treatment of the channelsof the study in 2014

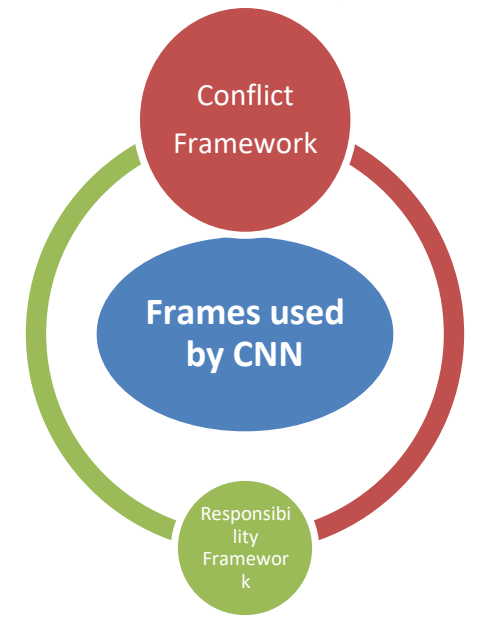

Fig.3: Frames used in the media of CNN in 2014 


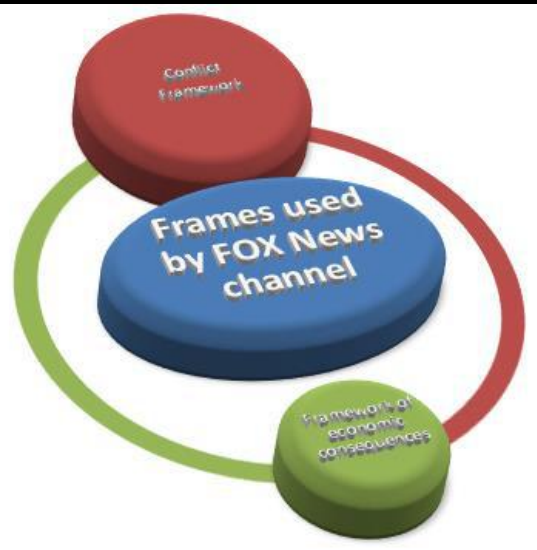

Fig.4: Frameworks used in media of FOX NEWS in 2014

Frameworks used in the media treatment of the two channels in 2017

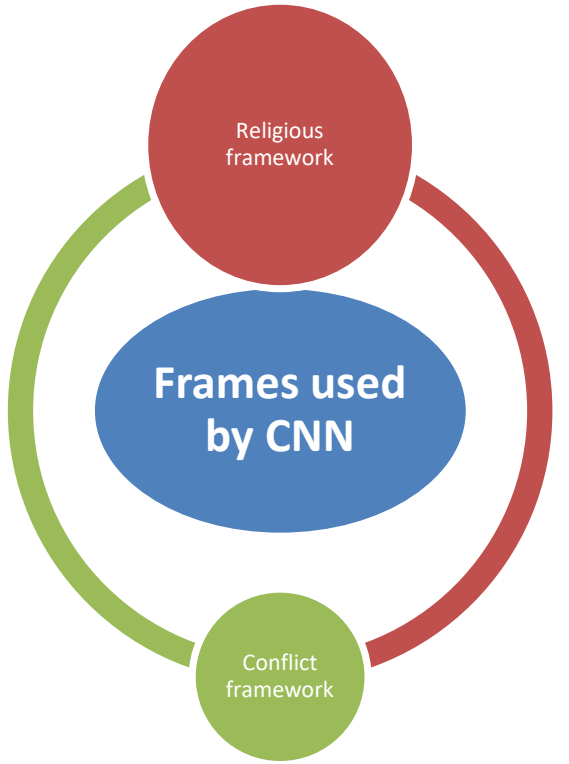

Fig.5: Frames used in the media of CNN in 2017

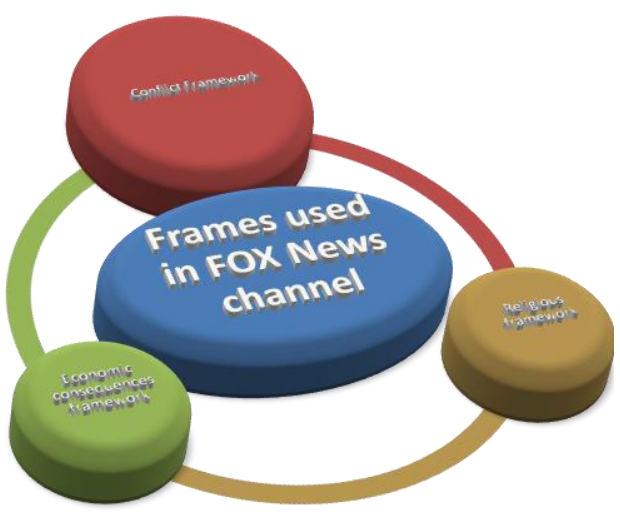

Fig.6: Frameworks used in media of FOX NEWS in 2017 